\title{
Evaluating the Effects of Improving Forest Road Standards on Economic Value of Forest Products
}

\author{
Abdullah E. Akay, Hasan Serin, John Sessions, Ebru Bilici, Mehmet Pak
}

\begin{abstract}
Forest roads are the key infrastructures that provide access to forest areas for sustainable management, protection, and utilization of forest resources. In order to benefit from the important functions of forest roads, they should be built in with adequate technical road standards. The road network with low technical standards require more frequent major repairs to ensure continues access to forest resources. In addition, only small trucks with low load capacity can move on the low standard roads. Furthermore, the low road standards limit the truck speed that increases vehicle travel time. These negative effects increase the transportation costs which are an important part of the timber production costs in Turkey. Thus, improving the road standards and developing forest transportation planning should be evaluated together in the most appropriate way. Large logging trucks with high load capacity are generally preferred for efficient transportation of wood-based forest products. In Turkey, large logging trucks, however, cannot operate on the most of the forest roads because insufficient technical road standards (road width, curve radius, surface materials, road structures) limit the maneuverability of large logging trucks. In this study, the objective is to determine the effects of improving forest road standards on total net profit of forest products by using the NETWORK 2000 program, a heuristic approach for solving forest transportation problems. Three Forest Enterprise Chiefs (FECs) located in Mustafakemalpaşa Forest Enterprise Directorate (FED) in Bursa Forest Regional Directorate were selected as the study area. The digital data layers for forest road network was generated by using ArcGIS 10.4 software. In the solution process, firstly, the optimum routes that minimize the transportation cost and maximize the total net profit of forest products on existing forest road networks were investigated for a truck type (15 ton) currently used in the region. In the second case, forest transportation was planned for the high load capacity truck (29 ton) moving on the forest roads with improved standards. In the first case, the transportation costs and annual major repair costs were considered in the calculation of the net profit of forest products, while one time cost of road improvement activities (i.e. road improvement construction, road structure installation, road surface construction) and annual maintenance costs were considered along with transportation costs in the second case. In both cases, the costs of other forest operations (i.e. felling, logging, etc.) were not considered since it was assumed that they do not vary with the forest transportation alternatives. As a result of the transportation plan developed for high load capacity truck, the annual transportation cost decreased by $46.85 \%$ comparing to the local logging trucks with low load capacity. Using improved road standards, the total road costs computed for the time period of 30 years (i.e. the average expected life cycle of forest roads) were reduced by $4.64 \%$. The total net profit of forest products transported by using a high load capacity truck was 473340 Euro more than that of using low load capacity truck on the existing forest road network. Thus, improving road standards might result in some additional costs in the road construction stage, but total net profit of forest products increase since transportation costs along with maintenance and repair costs considerably decrease in the long term.
\end{abstract}

Keywords: forest roads, forest products, timber hauling, NETWORK 2000 


\section{Introduction}

Forest roads are the basic facilities that enable safe and effective access to the forest for the purpose of carrying out main forestry activities such as timber extraction, forest transportation, forest protection, afforestation, and wildlife management activities throughout the year (Akay and Sessions 2005). The forest road network should be constructed in such a way that they do not have accessibility problems, excessive maintenance and construction needs, and high total road costs. In areas where the road network is inadequate and road standards are low, forest transportation costs, which constitute a significant part of the production costs of forest products, potentially increase. In Turkey, forest transportation cost is about $40 \%$ of the total amount spent on the management of forest resources (Acar 1998). The cost of forest transportation is of great importance in other European countries such as Finland, where road transport represents $76 \%$ of all roundwood transportation (Strandström 2016). Generally, logging trucks are preferred for transporting forest products (Acar and Eroğlu 2001). The most important factors affecting the unit cost of timber transportation include road gradient and length, road type, and road condition, which directly affect the truck travel time. Besides, timber transportation costs are affected by the load capacity of the trucks since it reflects the efficiency of timber transportation.

The wood-based forest products extracted from the harvest unit are first carried to temporary storage places called landing areas and then transported to the forest depots over the road network. The majority of forest roads (66\%) in Turkey are Type-B secondary forest roads, which are usually subject to annual major repair needs due to low road standards (GDF 2012). On these roads, there are some factors that limit the maneuverability of vehicles with high carrying capacity (Buğday and Menemencioğlu 2014). Firstly, the standard subgrade width and ditch width of Type-B secondary forest roads are $4 \mathrm{~m}$ and $1 \mathrm{~m}$, respectively. The minimum horizontal curve radius is $12 \mathrm{~m}$ and the road gradient is limited to $9 \%$. The maximum road gradient can be up to $12 \%$ in extreme cases and only for short road sections (Erdaş 1997, Gümüş et al 2019).

Another problem on the Type-B forest roads is the lack of road structures, which causes deterioration on the roads and affects the vehicle traffic flows. Since the use of heavy vehicles with high load capacity directly increases the total vehicle weight on forest roads, the need for road surface material becomes an important issue. In a study conducted by Buğday and Menemencioğlu (2014) in western Turkey, the standards of the existing Type-B forest roads were exam- ined to identify the problems encountered in forest roads with respect to commonly used logging trucks. As a result of the study, it was found that the existing roads could not meet the standards required by the large size logging trucks. It was suggested that the road structures, which are the sources of many problems on the existing roads, should be installed at the right locations. Also, it was reported that the curve radius and widening should be adjusted to allow logging trucks to safely operate on the forest roads.

In order to solve the problems encountered on forest roads, it is important to improve the existing forest road standards by reconstructing horizontal curves for safe and easy maneuvering of large logging trucks, restructuring road surface layer to provide sufficient traction force, and installing adequate road structures where necessary along the roadway. For the new roads to be constructed, it is important to construct roads with high standards at the beginning by considering suitable curve radius, appropriate road surface, and road structures of the right type and sizes (Karabenli 2018).

When the forest road standards are low, the contractors who prefer large logging trucks in forest transportation activities face difficulties in reaching the landing areas, and therefore they cannot participate in timber sales in these regions. Thus, improving the road standards and developing forest transportation planning should be evaluated together in the most appropriate way. Using traditional transportation planning methods, which are mainly based on the experience of the planner, it is challenging to develop the most suitable transportation plan. With developments in computer-aided methods and modern mathematical algorithms, it is much easier to identify the best set of routes to solve the forest transportation problem (Akay and Kılıç 2015). In this context, network analysis is widely used to solve complex engineering problems such as determining the shortest path, finding the lowest cost, determining the alternative with the maximum value flow and developing the most economical transportation plan.

In forest transportation planning, the NETWORK program (Sessions 1985) is one of the first software used to investigate the lowest cost route between landing area and forest depots. It has been widely used in various forestry activities, forest industry, and scientific researches particularly in Pacific North West region. Then, Chung and Sessions (2001) developed NETWORK 2000, a Windows-based version of this software, to improve the functionality of the user interface and increase the size of the problem to be solved (i.e. 20000 links, 20000 nodes and 5000 entry nodes). In addition, its solution capacity was improved 
using additional »heuristic« solution techniques within the alternative methods.

Ghaffarian and Sobhani (2007) implemented the timber extraction model, developed by the step-wise regression method, to estimate the skidding cost per cubic meter in a sample field with 39 nodes. In this study, an existing forest road network in a research forest in northern Iran was evaluated using network analysis and then timber volume and road cost were calculated for each node. After entering the data into NETWORK 2000, »Simulated Annealing « and »Great Deluge « algorithms were used to find the best solution in optimizing the cost of timber extraction from the region. As a result of the study, it was found that the best solution for the timber extraction operation using cable skidding can be found effectively by NETWORK 2000 after 45 repetitions.

In a study conducted by Akay and Süslü (2017), a Geographical Information System (GIS) based decision support system was used to determine the optimum route that minimizes the cost of transporting forest products. In the solution stage, alternative routes that provide access from the landing areas to the existing forest depots were identified and the most appropriate route with minimum transportation cost was found among them. It was reported that the trans- portation costs were significantly lower in forestry directorates where there were a number of forest depots within the borders. The distance between forest depots and possible landing areas was observed to significantly affect transportation costs.

In this study, NETWORK 2000 was used to examine the effects of improving forest road standards on forest road cost, forest transportation costs, and net profit of forest products. In the first case, the optimum transportation plans that minimized transportation cost and maximized net profit of forest products were developed for the truck type (15 ton) currently used in the region by considering the existing Type-B forest road standards. Then, the forest transportation was planned for the high load capacity truck ( 29 ton) by considering the improved standards on road subgrade width, superstructure width, and minimum curve radius. For both cases, the net present value (NPV) of minimum transportation cost and maximum net profit were computed for the average expected life cycle of forest roads.

\section{Material and Methods}

\subsection{Study Area}

The study area is located in three FECs within the border of Mustafakemalpaşa FED in the city of Bursa

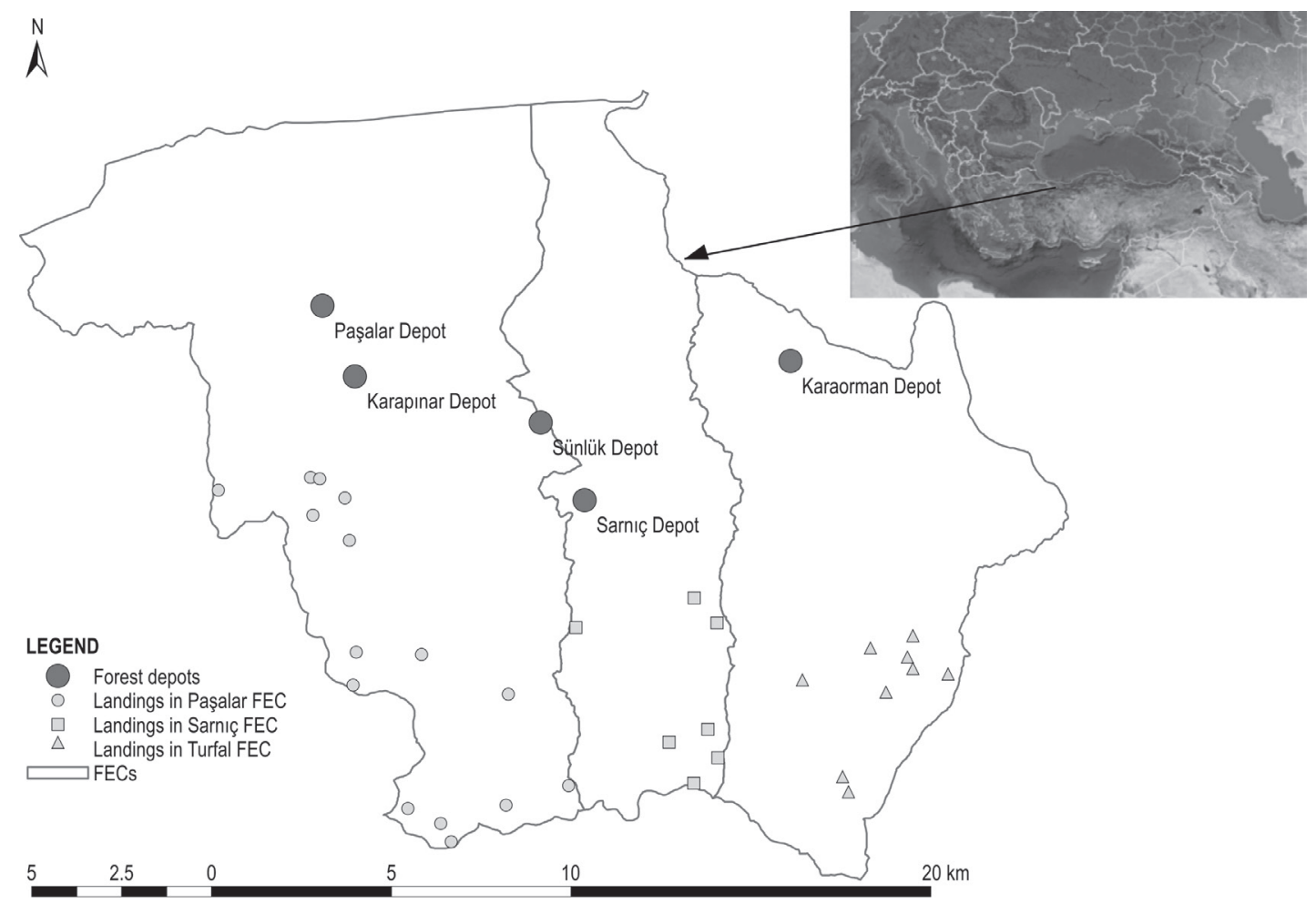

Fig. 1 Forest depots and landing areas in the study area 
in northwest Turkey. The information about the forest products such as their types (log, mine pole, industrial wood, pulp wood), sale prices, quantities, and landing locations were obtained from the FED. In the study area, there are five forest depots in which three depots (Paşalar, Karapınar, Sünlük Depots) are in the Paşalar FEC, one (Karaorman Depot) in the Turfal FEC and one (Sarnıç Depot) in the Sarnıç FEC. Forestry products are delivered to these depots from a different number of landing areas in three FECs. There are 15 landings in the Paşalar, seven landings in Sarnıç, and nine landings in Turfal FECs (Fig. 1).

\subsection{Road Network Data}

In this study, the map of the road networks was generated based on the forest management maps and topographic maps using ArcGIS 10.4 program. In the road network map, roads were classified into three types: asphalt, gravel, and Type-B road (unsurfaced) based on topographic maps of the study area. The roads formed with the combination of sand, gravel and clay as a binder and stabilized with lime, cement or bituminous substances are called gravel roads. On asphalt roads, a pavement consisting of hydrocarbon mixtures is used in order to protect the road subgrade against water and shear forces and increase resistance (Erdaş 1997).

The average transportation speed over the roads was calculated based on the road types, road conditions (good, medium, and poor), and the technical specifications of the trucks to be evaluated for timber transportation. Field observations were conducted in the study area to determine the conditions of the roads. In the field observations, the road network was divided into road sections by considering a road part between two consecutive junctions. The road condition for each section was determined based on four factors including average road gradient, number of horizontal curves, road surface condition (i.e. displaced and/or worn out road surface), and subgrade condition (i.e. deformations and deep ruttings). For each road section, firstly, scores from 1 to 3 were given to each factor affecting the road condition, and total score was computed for each section. Then, average score was computed for each section to come up with road condition. Table 1 shows the evaluation table used for the determination of the road condition and the decision matrix prepared for the specified factors.

\subsection{Network Analysis}

Various mathematical optimization methods have been developed to minimize transportation costs and to determine the route with the maximum net profit
Table 1 Road condition assessment table and decision matrix developed in this study

\begin{tabular}{|c|c|c|c|}
\hline \multicolumn{4}{|c|}{ Road condition assessment table } \\
\hline \multicolumn{4}{|l|}{ Forest enterprise directorate/chief: } \\
\hline \multicolumn{4}{|l|}{ Date: } \\
\hline \multicolumn{4}{|l|}{ Road type: } \\
\hline \multicolumn{4}{|l|}{ Road section number: } \\
\hline & Score $=1$ & Score $=2$ & Score $=3$ \\
\hline Factors & \multicolumn{3}{|c|}{ Type-B forest road (unsurfaced) } \\
\hline Road gradient & $>10 \%$ & $8-10 \%$ & $<8 \%$ \\
\hline Number of curves & $>2$ & 2 & 1 \\
\hline Road surface & Very poor & Poor & Good \\
\hline Subgrade & Very poor & Poor & Good \\
\hline Factors & \multicolumn{3}{|c|}{ Gravel road } \\
\hline Road gradient & $>6 \%$ & $4-6 \%$ & $<4 \%$ \\
\hline Number of curves & $>1$ & 1 & 0 \\
\hline Road surface & Very poor & Poor & Good \\
\hline Subgrade & Very poor & Poor & Good \\
\hline Factors & \multicolumn{3}{|c|}{ Asphalt road } \\
\hline Road gradient & $>4 \%$ & $3-4 \%$ & $<3 \%$ \\
\hline Number of curves & $>1$ & 1 & 0 \\
\hline Road surface & Very poor & Poor & Good \\
\hline Subgrade & Very poor & Poor & Good \\
\hline Factors & \multicolumn{3}{|c|}{ Decision matrix } \\
\hline Road gradient & & $\begin{array}{l}\text { Road } \\
\text { surface }\end{array}$ & \\
\hline Number of curves & & Platform & \\
\hline \multicolumn{4}{|l|}{ Total score: } \\
\hline If average score is ( $\Sigma$ Total Point/4): & $<1.5$ & $\begin{array}{c}\text { between } \\
1.5 \text { and } 2.5\end{array}$ & $>2.5$ \\
\hline Then road condition is: & Poor & Medium & Good \\
\hline
\end{tabular}

(Akay and Süslü 2017). The most common method is network analysis, where the optimum route is determined based on a road network system (Başkent 2004). The system is composed of the links and the nodes where the links intersect. In this study, NETWORK 2000 was used for network analysis, where links in the road network represented road sections and each link value represented the transportation cost for the associated road section. In the application of NETWORK 2000 program, criteria such as landing areas, different forest products, alternative routes and road standards, 


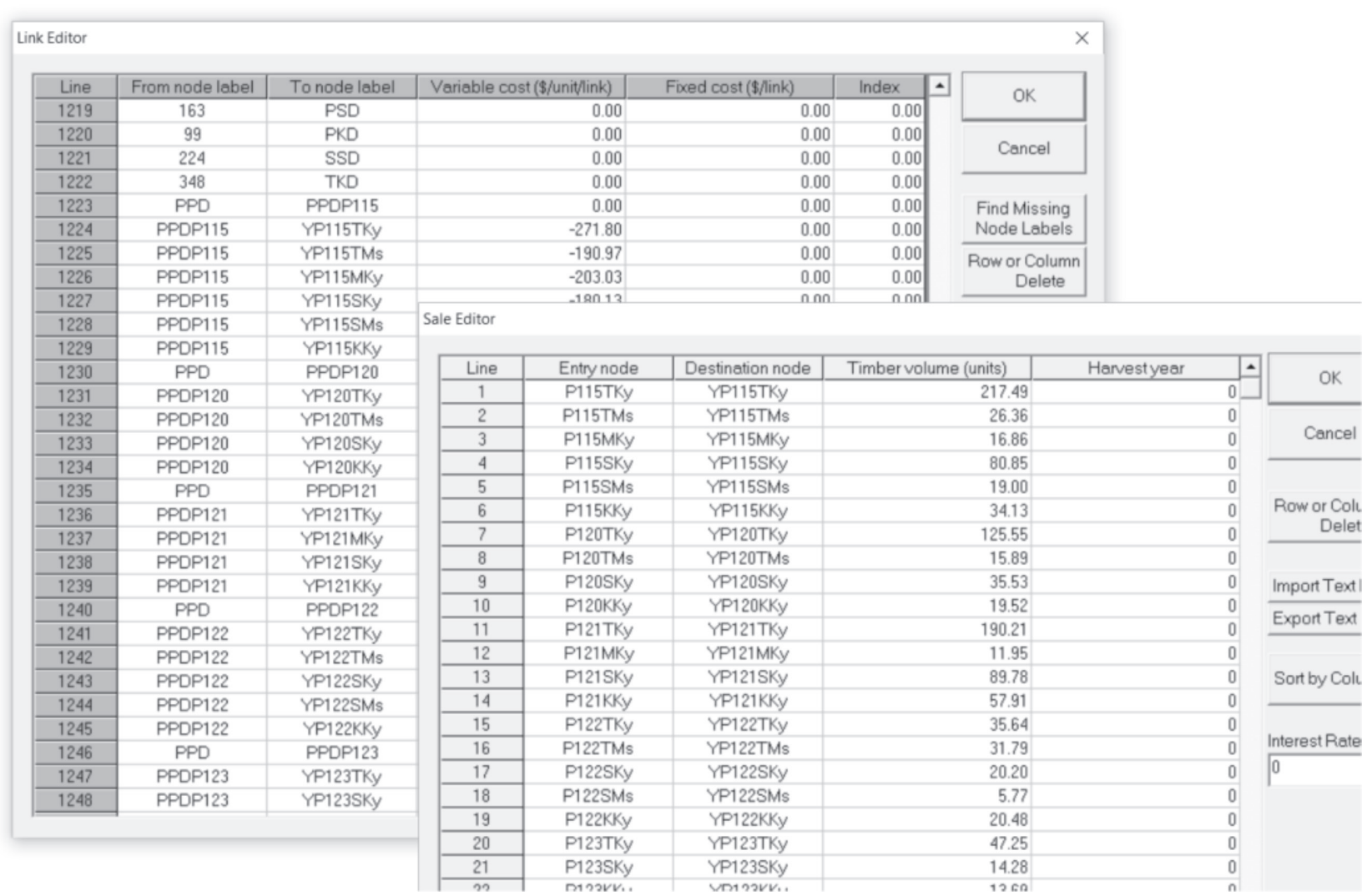

Fig. 2 "Link» and »Sale» table windows on NETWORK 2000 interface

alternative forest depots, minimum cost and maximum net profit were taken into consideration. The program has two data entry table windows including »Link« and »Sale« (Fig. 2).

The starting node and the ending node of the road sections were entered in the »Link« table window. The transportation costs were to be entered in the »Variable cost « column in the table window. The variable transportation cost refers to cost of the unloaded truck to travel over the road section plus the cost of the loaded truck to travel over the road section in the reverse direction. This assumes that the route that the unloaded truck follows is the same as the one followed by the loaded truck. If a new road section needs to be added into the road network or an existing road section needs to be improved through road improvement construction, road structure installation, and road surface construction before wood transport can begin, the cost of the construction activities is specified as fixed costs. The fixed costs were to be entered in the »Fixed cost $«$ column in the »Link « table window. Since NETWORK
2000 is set up to minimize costs, in the data entry stage, the costs were entered into the network database as positive values and timber sale prices as negative values. NETWORK 2000 then solves to find the lowest cost which is the maximum net profit. When the program determined the route that minimized the total cost, which was the sum of the total values of costs and sale prices (sale price $>$ costs) in the network system, the optimum route that maximized the net profit was determined.

The beginning nodes (Entry Node) and ending nodes (Destination Node) of the entire network system and the quantity of products (Timber Volume) transported in the network were entered in the »Sale « table window. For each wood-based products (log, mine pole, industrial wood, pulp wood) evaluated in the study, unique entry nodes were specified in the "Entry Node« column of the "Sale« table window. Then, destination nodes representing all of the forest products at each forest depot were specified in the "Destination Node« column of the table window. In 
addition, the volume of forest products produced and transported over the network system were entered in the »Timber Volume« column. NETWORK 2000 is able to compute net present value of transported forest products for various time periods by defining the interest rate and harvesting year at the »Sale « table window. In this study, an interest rate of $12.25 \%$ (CBRT 2019) was used for a time period of 30 years, which is the average expected life cycle of forest roads (Enache and Stampfer 2015).

\subsubsection{Transportation Costs}

After determining the existing road conditions, vehicle speed was assigned for the three road types with three road conditions based on the previous studies and interviews with local experienced truck drivers (Akay and Erdaş 2007) (Table 2). Truck speed represents the average value of the loaded truck speed and the unloaded truck speed for both truck types. Within the scope of the study, a logging truck (15 ton) commonly used in the region and a sample logging truck of high load capacity (29 tons), which is currently used in some regions of Turkey where forest road standards are suitable, was taken into consideration (Figs 3 and 4).

In the next step, the unit transportation cost $\left(E u r o / \mathrm{m}^{3}\right)$ for each road section was computed based on the hourly unit cost of the truck (Euro/hour), load capac-

Table 2 Average truck speed for road types and conditions ( $\mathrm{km} / \mathrm{hour)}$

\begin{tabular}{|l|c|c|c|}
\hline \multirow{2}{*}{\multicolumn{2}{|c|}{ Road type }} & \multicolumn{3}{|c|}{ Road conditions } \\
\cline { 2 - 4 } & Good & Medium & Poor \\
\hline Asphalt road & 60 & 50 & 40 \\
\hline Gravel road & 40 & 30 & 20 \\
\hline Type-B forest road & 25 & 20 & 15 \\
\hline
\end{tabular}

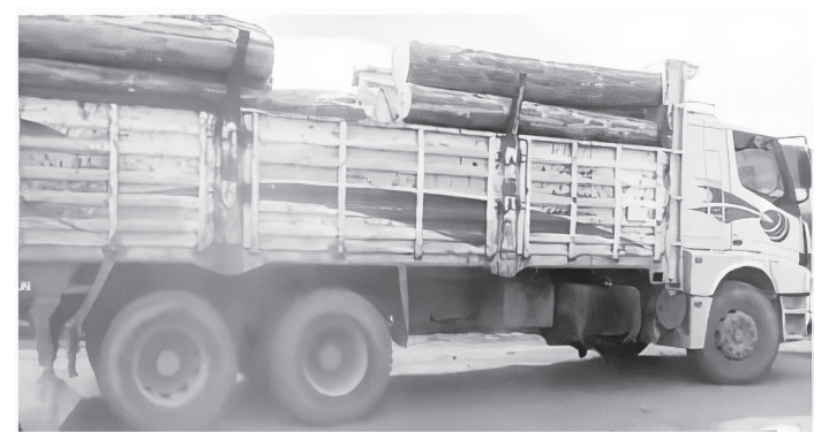

Fig. 3 Logging truck (BMC Pro 522) commonly used in the region

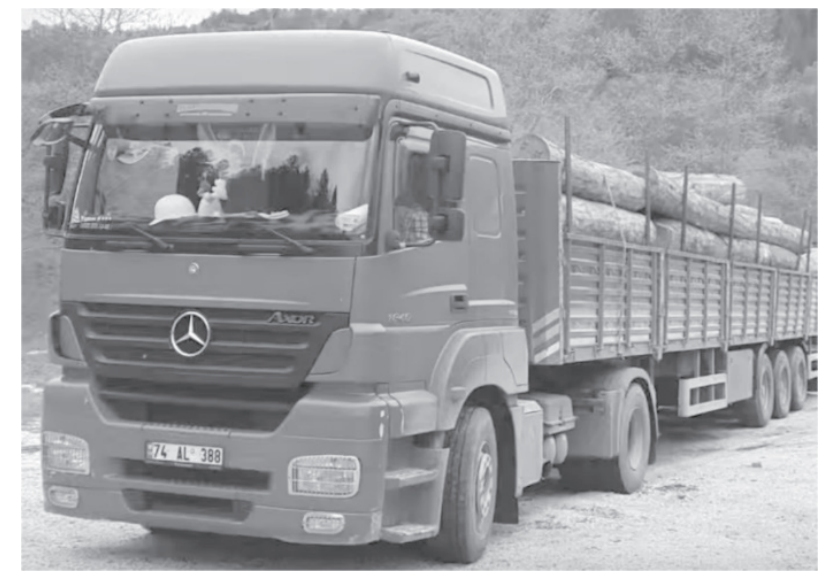

Fig. 4 High load capacity logging truck (Mercedes Axor 1840LS) evaluated in the study

ity of the truck $\left(\mathrm{m}^{3}\right)$ and truck operating time (hours) as follows (Akay and Erdaş 2007):

$$
T C=H C /((L C / t))
$$

Where:

TC unit transportation cost for road section, Euro $/ \mathrm{m}^{3}$

HC hourly unit cost of the truck, Euro/hour

LC load capacity, $\mathrm{m}^{3}$

$t$ round trip truck operating time per section, hours

The hourly unit cost, obtained from Mustafakemalpaşa FED, was 9.37 Euro/hr ${ }^{3}$ for the common logging truck. For the logging truck of high load capacity, hourly unit cost was $14.57 \mathrm{Euro} / \mathrm{hr}^{3}$ based on the information obtained from the local forest sector. Then, the truck operating time was determined as follows (Akay and Erdaş 2007):

$$
t=2 L(1+D T) / V)
$$

$L \quad$ road length per section, $\mathrm{km}$

$V \quad$ average truck speed over road section, $\mathrm{km} /$ hour DT delay time, asphalt: $5 \%$, gravel: $10 \%$, Type-B forest road: $15 \%$

\subsubsection{Major Road Repair and Road Improvement Costs}

Type-B forest roads with the lack of road structures and lack of adequate road surface material are usually subject to major repair every year due to deterioration on the road template especially during rainy seasons. In this study, it was assumed that major repair was necessary particularly for the Type-B forest road sections with poor road conditions. The cost of annual major repair was computed based on the unit price (2400 Euro/km) obtained from the FED and total 
length of poor forest roads along the optimum route. Then, the discounted sum of annual major repair costs was computed for an average expected life cycle of forest roads and entered as a fixed cost.

In order to improve the existing forest roads to higher standards, a one-time cost of road improvement activities (i.e. road improvement construction,

Table 3 Unit price list for road improvement construction

\begin{tabular}{|l|c|c|}
\hline \multicolumn{1}{|c|}{ Type of work } & Unit & Unit price, Euro \\
\hline $\begin{array}{l}\text { Excavation and use of all types } \\
\text { of soil ground with bulldozer }\end{array}$ & $\mathrm{m}^{3}$ & 0.48 \\
\hline $\begin{array}{l}\text { Excavation and use of all kinds } \\
\text { of hard soil ground with bulldozer }\end{array}$ & $\mathrm{m}^{3}$ & 0.82 \\
\hline $\begin{array}{l}\text { Excavation and use of all kinds } \\
\text { of soft rock with excavator }\end{array}$ & $\mathrm{m}^{3}$ & 1.71 \\
\hline $\begin{array}{l}\text { Excavation and use of all kinds } \\
\text { of hard rock with excavator }\end{array}$ & $\mathrm{m}^{3}$ & 1.89 \\
\hline Leveling on all soil ground & $\mathrm{km}$ & 272.53 \\
\hline Leveling on all hard soil ground & $\mathrm{km}$ & 340.66 \\
\hline Leveling on all rocky ground & $\mathrm{km}$ & 545.05 \\
\hline
\end{tabular}

Table 4 Unit price list for road structure installation

\begin{tabular}{|l|c|c|}
\hline \multicolumn{1}{|c|}{ Type of manufacturing } & Unit & $\begin{array}{c}\text { Unit price } \\
\text { Euro }\end{array}$ \\
\hline $\begin{array}{l}\text { Drainage, ditch and wall foundation on any depths } \\
\text { and any type and class of ground } \\
\text { (except for the excavation of the drainage ditch and } \\
\text { wall foundation in the landslide area) }\end{array}$ & $\mathrm{m}^{3}$ & 3.72 \\
\hline Blockage with excavation stone & $\mathrm{m}^{3}$ & 8.78 \\
\hline $\begin{array}{l}\text { Non-ferrous concrete in dry or water in all kinds of } \\
\text { construction (with C 25/30 Ready Mixed Mortar) }\end{array}$ & $\mathrm{m}^{3}$ & 39.82 \\
\hline $\begin{array}{l}\text { 8-12 mm thin ribbed steel supply and workmanship } \\
\text { for reinforced concrete (excluding shipping) }\end{array}$ & ton & 637.11 \\
\hline 80 cm ready-made reinforced concrete culvert (2 m) & $\mathrm{m}$ & 29.00 \\
\hline Workmanship for culvert installation & $\mathrm{m}$ & 8.38 \\
\hline Reinforced concrete formwork (materials) & $\mathrm{m}^{2}$ & 5.88 \\
\hline Culvert transportation (2 m culvert) (from 25 km) & piece & 16.00 \\
\hline Sand-gravel transportation (from 15 km) & $\mathrm{m}^{3}$ & 12.00 \\
\hline Iron transportation (from 25 km) & ton & 13.00 \\
\hline
\end{tabular}

Table 5 Unit price list for road surface construction

\begin{tabular}{|l|c|c|}
\hline \multicolumn{1}{|c|}{ Type of Work } & Unit & Unit price, Euro \\
\hline Road surface irrigation with water tank & ton & 1.77 \\
\hline Compression with a rubber-tired roller (7-8 tons) & $\mathrm{hr}$ & 13.75 \\
\hline $\begin{array}{l}\text { Subbase and base material supply with } \\
\text { unbroken and non-sieved gravel material }\end{array}$ & $\mathrm{m}^{3}$ & 0.99 \\
\hline Material spreading with machines & $\mathrm{m}^{3}$ & 0.24 \\
\hline Material loading and unloading with machine & $\mathrm{m}^{3}$ & 0.78 \\
\hline Material transportation (from $5 \mathrm{~km}$ ) & $\mathrm{m}^{3}$ & 5.29 \\
\hline
\end{tabular}

road structure installation, road surface construction) and annual maintenance costs were evaluated for the total length of Type-B forest roads on the optimum route. Table 3 indicates the unit price of the road improvement activities obtained from the FED. In improved road standards, the road subgrade width, superstructure width, and minimum curve radius were $5 \mathrm{~m}, 4 \mathrm{~m}$, and $20 \mathrm{~m}$, respectively, (as stated in Gümüş et al. 2019), while they were $4 \mathrm{~m}, 3 \mathrm{~m}$, and $12 \mathrm{~m}$ in existing road standards. Information on the road structures and their dimensions were recorded for the associated sections and marked on the road network map using ArcGIS 10.4 software. Then, the costs of road structures were calculated by using the current unit prices obtained from the FED (Table 4).

As a road structure, ready-made reinforced concrete culverts were added where necessary. For some points, the extra costs for head and wall construction was evaluated during culvert installation. The diameter of the concrete pipes was $80 \mathrm{~cm}$ and their length was determined as $6 \mathrm{~m}$ or $8 \mathrm{~m}$ according to the terrain conditions. The construction costs of the road surface (with $30 \mathrm{~cm}$ thickness) were determined based on the road dimensions, amount of surface material, and the costs of road surfacing operations. Table 5 indicates the unit prices of surface materials and labor obtained from the FED. Then, the cost of annual maintenance was computed based on the unit price (36 Euro $/ \mathrm{km}$ ) obtained from the FED. Finally, total cost of improved roads was computed for each section considering one time cost of road improvement activities and the discounted cost of total annual maintenance costs for the average expected life cycle of forest roads.

\subsubsection{Total Net Profit of Forest Products}

The optimum transportation plan that maximizes net profit of forest products was developed for a truck 
Table 6 Amount of forest products produced in each FEC in the study area $\left(\mathrm{m}^{3}\right)$

\begin{tabular}{|l|c|c|c|c|c|}
\hline $\begin{array}{c}\text { Forest } \\
\text { depots }\end{array}$ & Species & Logs & $\begin{array}{c}\text { Mine } \\
\text { pole }\end{array}$ & $\begin{array}{c}\text { Industrial } \\
\text { wood }\end{array}$ & $\begin{array}{c}\text { Paper } \\
\text { wood }\end{array}$ \\
\hline \multirow{4}{*}{ Paşalar } & Beech & 9782.74 & 724.655 & 2622.12 & 23.975 \\
\cline { 2 - 6 } & Oak & 101.7 & - & 54.879 & - \\
\cline { 2 - 6 } & Fir & 84.635 & - & - & - \\
\cline { 2 - 6 } & Hornbeam & 38.343 & - & - & - \\
\cline { 2 - 6 } & Black pine & - & - & - & 596.7 \\
\hline \multirow{3}{*}{ Turfal } & Beech & 6696.81 & - & 1479.45 & 1049.09 \\
\cline { 2 - 6 } & Oak & 157.09 & - & 201.87 & - \\
\hline \multirow{2}{*}{ Sarnıç } & Beech & 10600.11 & - & 2447.22 & 1244.20 \\
\cline { 2 - 6 } & Oak & - & - & 92.37 & - \\
\hline
\end{tabular}

Table 7 Average sales prices $\left(E u r o / \mathrm{m}^{3}\right)$ of forest products in each forest depot in the study area

\begin{tabular}{|c|c|c|c|c|c|}
\hline $\begin{array}{l}\text { Forest } \\
\text { depots }\end{array}$ & Species & Logs & $\begin{array}{l}\text { Mine } \\
\text { pole }\end{array}$ & $\begin{array}{c}\text { Industrial } \\
\text { wood }\end{array}$ & $\begin{array}{l}\text { Paper } \\
\text { wood }\end{array}$ \\
\hline \multirow[t]{5}{*}{ Paşalar } & Beech & 271.80 & 54.36 & 40.61 & 36.03 \\
\hline & Oak & 190.97 & 38.19 & - & 36.61 \\
\hline & Fir & 195.35 & 39.07 & - & - \\
\hline & Hornbeam & 205.45 & 41.09 & - & - \\
\hline & Black pine & - & - & - & - \\
\hline \multirow[t]{5}{*}{ Sünlük } & Beech & 262.92 & 52.58 & 41.17 & 38.78 \\
\hline & Oak & 198.31 & 39.66 & - & 32.09 \\
\hline & Fir & 222.40 & 44.48 & - & - \\
\hline & Hornbeam & 203.50 & 40.70 & - & - \\
\hline & Black pine & - & - & - & - \\
\hline \multirow[t]{5}{*}{ Karapınar } & Beech & 264.08 & 52.82 & 42.28 & 40.16 \\
\hline & Oak & 239.58 & 47.92 & - & 38.82 \\
\hline & Fir & 188.21 & 37.64 & - & - \\
\hline & Hornbeam & 204.10 & 40.82 & - & - \\
\hline & Black pine & - & - & - & - \\
\hline \multirow[t]{5}{*}{ Sarnıç } & Beech & 277.99 & 55.60 & 40.54 & 39.44 \\
\hline & Oak & 245.00 & 49.00 & - & 39.63 \\
\hline & Fir & 200.30 & 40.06 & - & - \\
\hline & Hornbeam & 202.91 & 40.58 & - & - \\
\hline & Black pine & - & - & - & - \\
\hline \multirow[t]{2}{*}{ Karaorman } & Beech & 280.27 & 56.05 & - & 39.91 \\
\hline & Oak & 228.42 & 45.68 & - & 36.54 \\
\hline
\end{tabular}

type (15 ton) currently used in the region by considering the existing road standards and for a high load capacity truck ( 29 ton) by considering the improved road standards. In the first case, the net profit of forest products was computed by subtracting the transportation costs and annual major repair costs from the total economic value of the forest products. On the other hand, transportation costs, road improvement costs, and annual maintenance costs were considered in the second case. In both cases, the costs of other forest operations (e.g. felling, skidding) were not considered as they do not vary with the road transportation alternatives. The total economic value of forest products was computed based on the amount of forest products and their sale prices in each forest depot (Table 6 and 7). Finally, the net present value (NPV) of maximum net profit was computed for the average expected life cycle of forest roads for both cases.

\section{Results and Discussion}

\subsection{Road Network}

Total road network length in the study area (Fig. 5) was calculated as $519 \mathrm{~km}$, most of the roads being Type-B forest roads $(70.71 \%)$, followed by asphalt paved roads $(17.73 \%)$ and gravel roads $(11.56 \%)$. In the study area, the actual road density was calculated as $24.29 \mathrm{~m} / \mathrm{ha}$. Considering the condition of road networks in the study area, $16.95 \%$ of roads were classified as good, $71.10 \%$ as medium and $11.95 \%$ as poor (Table 8). It was found that half of the asphalt paved roads were in good condition, $44.57 \%$ of them were in the medium and the remaining roads were in poor condition (5.43\%). Considering the gravel roads, it was determined that $41.67 \%$ of the roads were in good condition, $38.33 \%$ were in the medium and the remaining roads were in poor condition (20.00\%). On Type-B forest roads, most of the roads were in medium condition $(83.11 \%)$, while $12.26 \%$ were poor and $4.63 \%$ were in good condition.

Table 8 Road length data according to road types and conditions

\begin{tabular}{|l|c|c|c|c|c|}
\hline \multirow{2}{*}{$\begin{array}{c}\text { Road } \\
\text { types }\end{array}$} & \multirow{2}{*}{$\begin{array}{c}\text { Number } \\
\text { of sections }\end{array}$} & $\begin{array}{c}\text { Total road } \\
\text { length, } \mathrm{km}\end{array}$ & \multicolumn{3}{|c|}{$\begin{array}{r}\text { Road length according to } \\
\text { road conditions, km }\end{array}$} \\
\cline { 4 - 6 } & & & Good & Medium & Poor \\
\hline Asphalt & 114 & 92 & 46 & 41 & 5 \\
\hline Gravel & 61 & 60 & 25 & 23 & 12 \\
\hline $\begin{array}{l}\text { Type-B } \\
\text { forest road }\end{array}$ & 362 & 367 & 17 & 305 & 45 \\
\hline Total & 537 & 519 & 88 & 369 & 62 \\
\hline
\end{tabular}




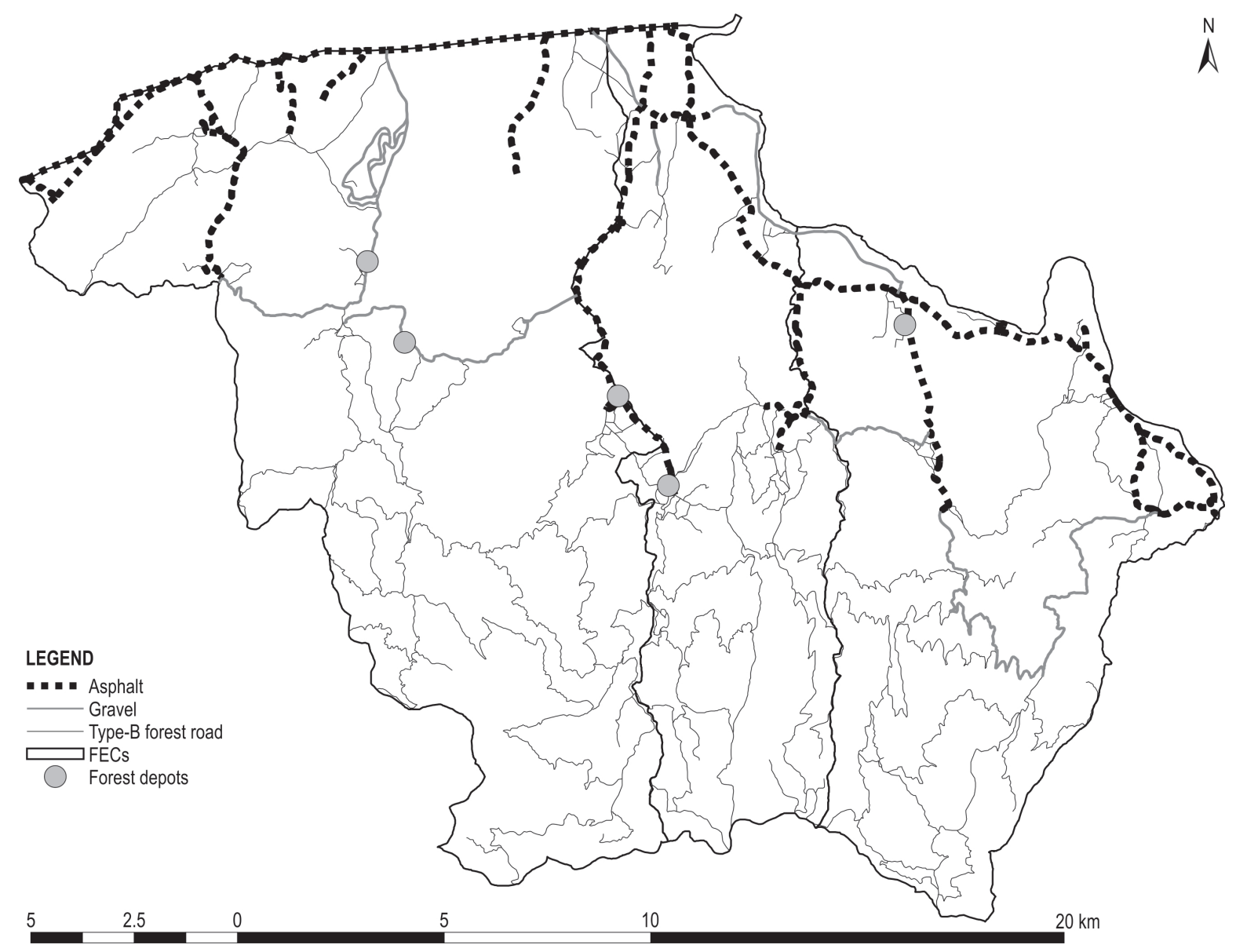

Fig. 5 Road network map

\subsection{Total Costs and Net Profits}

The potential effects of improving forest road standards on the economic value of forest products, transportation costs and road construction costs were analyzed using the NETWORK 2000 program. This program was selected because it can assist decision makers to determine not only the routes with the minimum transportation costs but also the routes with the highest net profit by considering sales prices of forest products (Akay and Erdaş 2007). In the solution process, the effects of using high load capacity logging trucks on transportation costs and total net profit were evaluated for the forest roads with improved standards. High load capacity trucks can haul more forest products at each trip, which potentially reduces the cost of transportation (Genç and Arıcak 2016).

\subsubsection{Existing Forest Roads}

In the first case, the optimum transportation plans that minimized transportation cost and maximized net profit of forest products was developed for a truck type
(15 ton) currently used in the region on the existing Type-B road standards. The NETWORK 2000 program minimized the total transportation cost to 27823 Euro. The program provides a report that indicates the information about the minimum transportation cost for forest products hauled from each landing area. The report also includes the total transportation cost and unit transportation cost for each forest product (Akay and Erdaş 2007). A sample transportation cost report of the optimum route for the beech logs $\left(3721.15 \mathrm{~m}^{3}\right)$ from one of the landings in Sarnıç FEC is shown in Fig. 6.

The existing forest roads with poor road conditions are subject to lack of road structures and lack of adequate road surface material, which leads to major repair every year. The results indicated that the annual major repair costs for the poor roads along the optimum route was 30096 Euro. Then, the discounted total annual major repair costs was computed as 964049 Euro for the average expected road life of 30 years.

After determining the transportation costs and annual major repair costs, the total net profit was 


\section{Detailed Sale Report :}

Sale Number : 1

${ }^{\star}$ Route

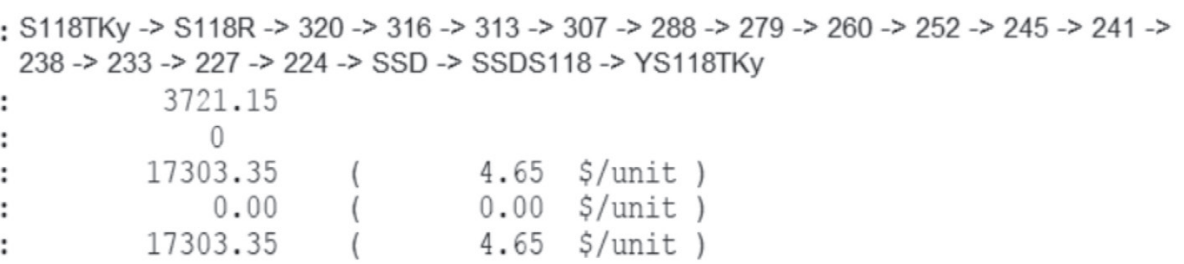

Fig. 6 A cost report (TRY) of the optimum transportation route for logs hauled from a sample landing on existing roads (1 TRY $=0.2$ Euro)

\section{Detailed Sale Report :}

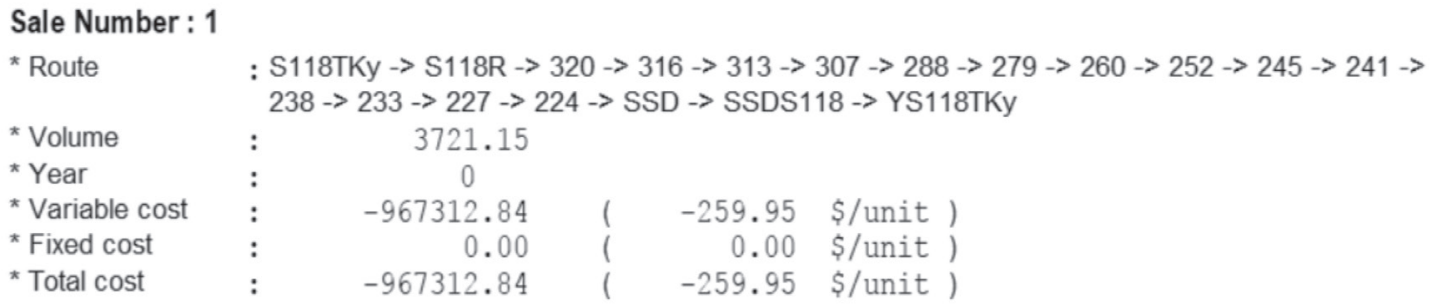

Fig. 7 A net profit report (TRY) of the optimum transportation route for the logs hauled from a sample landing on the existing roads (Negative values are interpreted as positive profit)

calculated based on the sale prices and amount of forest products. It was found that maximum annual net profit was 1647408 Euro and NPV of total net profit for the average expected road life was computed as 52770557 Euro. NETWORK 2000 also provides a report for the maximum net profit and unit net profit for forest products hauled from each landing area. Fig. 7 indicates a sample net profit report of the optimum route for the beech logs hauled from one of the landings in Sarnıç FEC.

\subsubsection{Improved Forest Roads}

The total transportation costs, road improvement costs (i.e. road improvement construction, road structure installation, road surface construction), and total net profit of forest products were determined for the case where Type-B forest roads in poor condition along the optimum route were converted to high standard forest roads. In this case, a large logging truck with high load capacity (29 ton) was considered for efficient transportation of forest products on roads with improved standard. The results indicated that the total transportation cost was reduced to 14787 Euro. Thus, the transportation plan developed by NETWORK 2000 for the high load capacity truck travelling on forest roads with improved standards decreased annual transportation cost by $46.85 \%$ comparing to the local logging trucks travelling on existing forest roads. Using logging trucks with high load capacity potentially increases the transportation efficiency which eventually leads to

\section{Detailed Sale Report :}

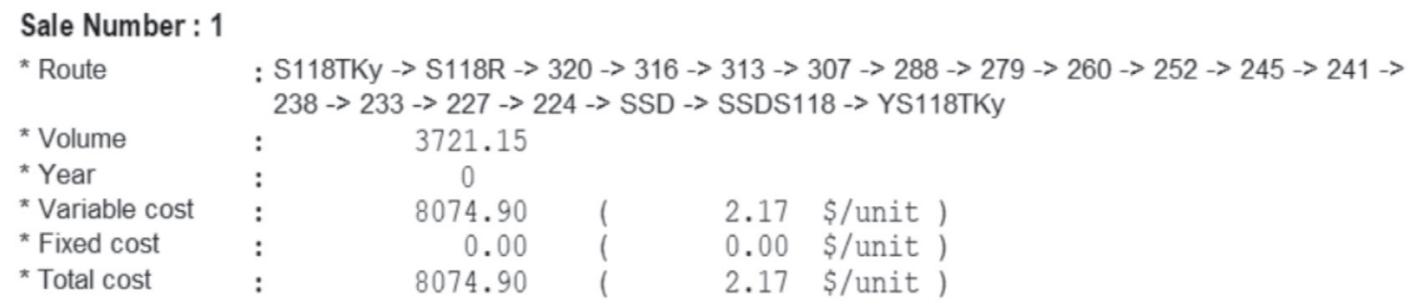

Fig. 8 A cost report (TRY) of the optimum transportation route for the logs hauled from a sample landing on the roads with improved standards 


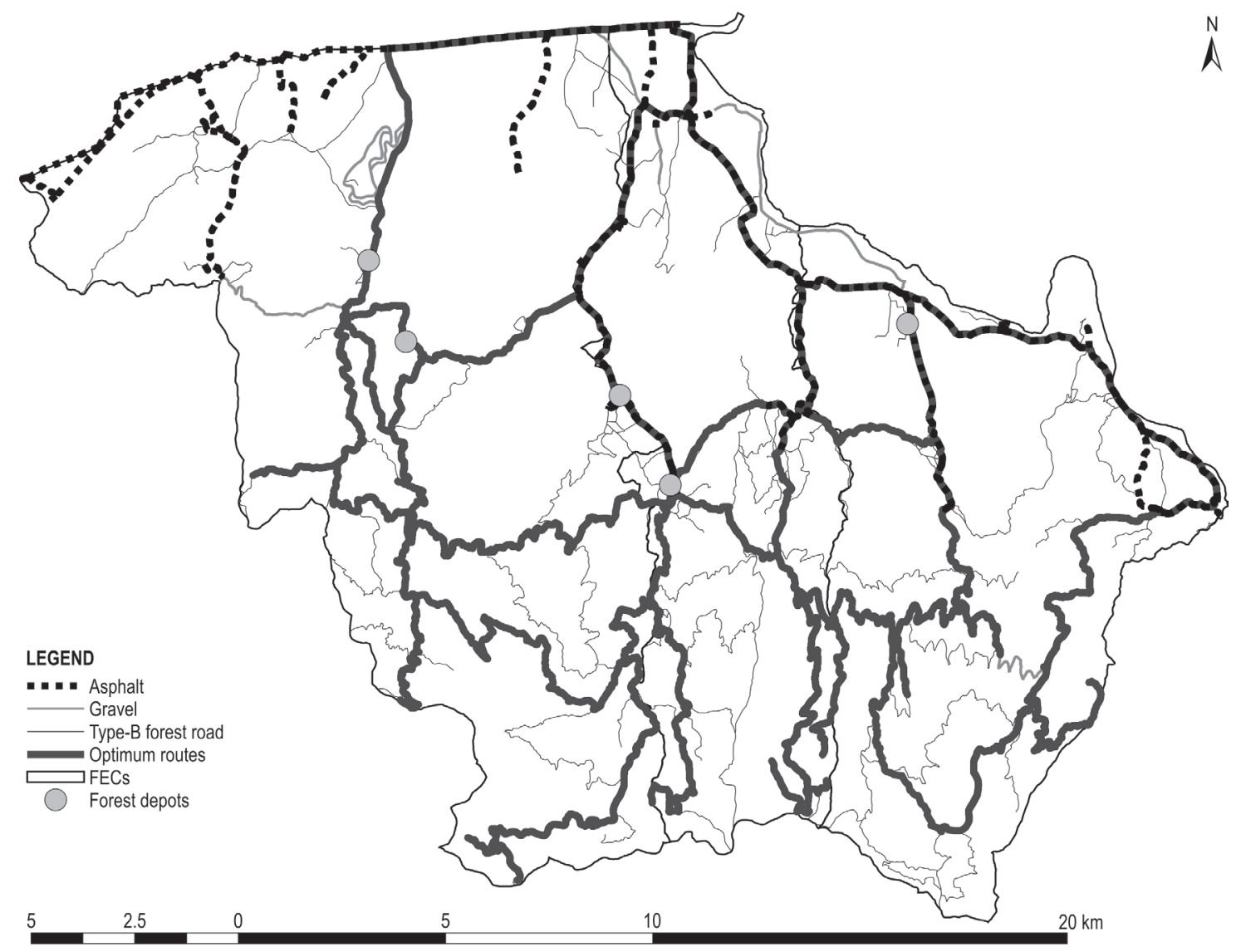

Fig. 9 Type-B forest roads to be improved within optimum routes

reduction in the forest transportation costs (Borre and Larsson 2011). Fig. 8 indicates a sample transportation cost report of the optimum route for the beech logs hauled from one of the landings in Sarnıç FEC.

The cost of road improvement activities (i.e. road improvement construction, road structure installation, and road surface construction) and annual maintenance costs were computed for Type-B forest roads on the optimum route. The forest roads, which were subject to improvement, are indicated in Fig. 9. It was found that the total length of Type-B forest roads on the optimum route was $89.32 \mathrm{~km}$, most of the roads being in moderate condition (82.59\%), and $14.04 \%$ and $3.37 \%$ in poor and good condition, respectively. The location and costs of the road structures to be installed along the optimum route were determined based on the data obtained during the field observations. Reinforced concrete culverts should be placed at 142 locations; 124 culverts were to be $6 \mathrm{~m}$ long, while $18 \mathrm{cul}$ verts were $8 \mathrm{~m}$ long (Fig. 10). The total costs of road activities conducted one time at the time of road improvement and the cost of maintenance conducted every year are shown in Table 9. The results indicated that total cost of road improvement activities were 816273 Euro and annual maintenance cost was 3216 Euro. Then, the discounted total road cost was computed as 919274 Euro, which includes one time cost of road improvement activities and the discounted cost of annual maintenance costs for the average expected road life. Thus, for the case of improved road standards, the discounted total road costs for the average expected life cycle (30 years) of forest roads were reduced by $4.64 \%$.

At the last stage, NPV of total net profits were compared to determine the acceptability of investment on improving forest road standards. It was found that the NPV of total net profit of forest products was 473340 Euro more than that of using low load capacity truck

Table $\mathbf{9}$ The total costs of road improvement activities and annual maintenance

\begin{tabular}{|l|c|}
\hline \multicolumn{1}{|c|}{ Road improvement and maintenance activities } & Total costs, Euro \\
\hline Road improvement construction & 101746 \\
\hline Road structure installation & 105443 \\
\hline Road surface construction & 609083 \\
\hline Annual maintenance & 3216 \\
\hline
\end{tabular}




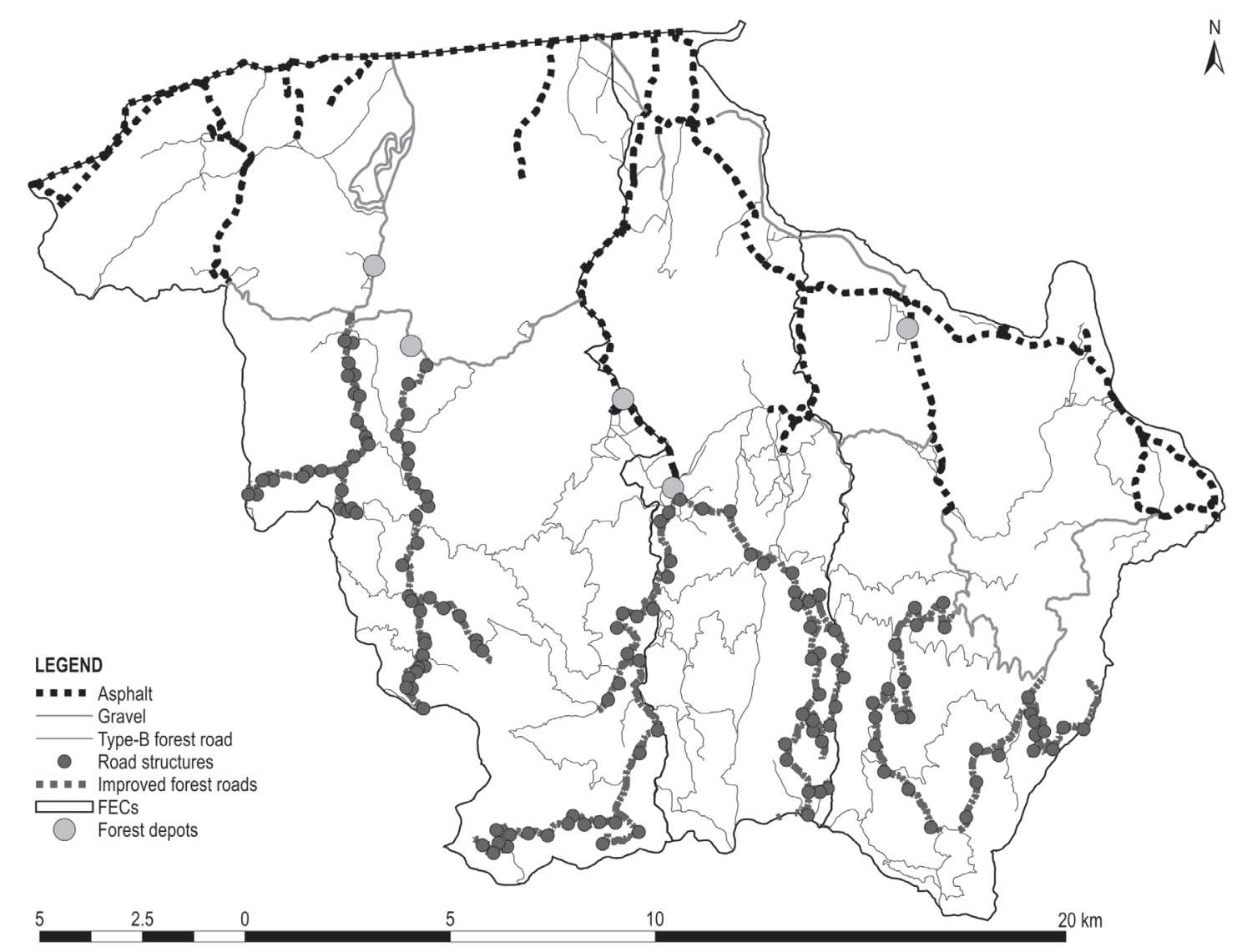

Fig. 10 Proposed locations of road structures along optimum routes

Detailed Sale Report :

Sale Number : 1

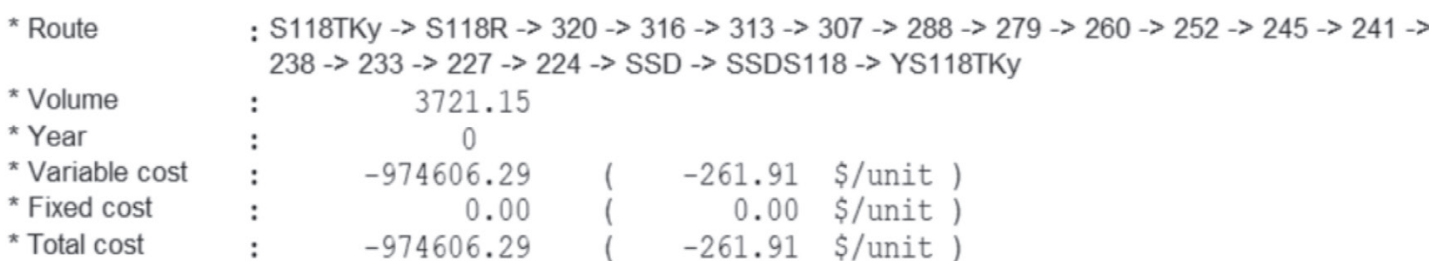

Fig. 11 A net profit report (TRY) of the optimum transportation route for logs hauled from a sample landing on roads with improved standards (Negative values are interpreted as positive profit)

on the existing road network, which revealed that the investment to be made on improving forest road standards was acceptable. A sample net profit report of the optimum route for the beech logs hauled from one of the landings in Sarnıç FEC is shown in Fig. 11.

\section{Conclusions}

The timber extraction and transportation of forest products are among the forestry activities that must be planned and implemented in harmony. The most im- portant factors affecting the efficiency of transportation, which constitutes a significant part of the total cost in the production of forest products, are the road type, road length, road condition, and the load capacity of logging trucks. In Turkey, it is not possible to use logging trucks with high load capacity on Type-B forest roads, which constitute an important part of the existing forest roads. The inadequacy of the technical standards, the lack of road structures and road surface material limit the maneuverability of high capacity trucks on these roads. 
Evaluating the Effects of Improving Forest Road Standards on Economic Value of Forest Products (245-258) A.E. Akay et al.

In this study, it was aimed to determine the effects of improving forest road standards on the economic value of forest products and forest transportation by using NETWORK 2000. For this purpose, firstly, total road costs, transportation costs, and total net profit were determined for a logging truck (15 tons) currently used in the region. Then, these three parameters were determined for a logging truck with high load capacity (29 tons) travelling on forest roads with improved standards.

In the study area, a total of five forest depots and 31 landing areas were taken into consideration within the borders of the three FECs located in the city of Bursa. In the study, the road networks, forest depots and landing areas in the study area were mapped by using ArcGIS 10.4 program. The average truck speed was calculated depending on the road types (asphalt, gravel and forest roads) and road conditions (good, medium and poor). The results indicated that the total length of forest roads on optimum route was $89.32 \mathrm{~km}$, most of the roads being in moderate condition $(73.77 \mathrm{~km})$, and $12.54 \mathrm{~km}$ and $3.01 \mathrm{~km}$ in poor and good conditions, respectively.

In the transportation plan developed for the high capacity truck traveling on forest roads with improved standards, the total transportation cost of forest products was decreased by $46.85 \%$ compared to the plan developed for the low capacity truck travelling on existing forest roads. Improving road standards causes additional costs in road construction stage, but total road costs decrease since maintenance and repair costs considerably decrease in the long term. In this study, it was found that the discounted total road costs for the average expected life cycle ( 30 years) of forest roads were reduced by $4.64 \%$ in the case of improved road standards. The present net value of forest products was also calculated for the 30-year period and the acceptability of the investment to be made in order to improve the forest road standards was investigated. The results indicated that change in net present value was greater than zero, so investments to improve the forest road standards would be appropriate.

Traditional methods, which are essentially based on the experience of the planners, are limited in terms of developing the most suitable transportation plan. However, it is possible to make significant savings in terms of time and money by using computer-aided decision support systems for developing transportation plans for forest products. Especially in productive forests with tree species of high economic value, it would be more appropriate to increase the standards of forest roads and make them suitable for the transportation of forest products using high capacity trucks. Since the high standard roads will positively affect forest access and transportation of forest products from landing to forest depots, the auction prices of forest products and therefore the net profit to be obtained from the forest products will be higher especially in the stumpage sales. Transportation of forest products using high capacity trucks in a shorter time will increase the overall value received from the forest products. In addition, the negative effects of insect and fungal pests on the products will be minimized as the forest products are kept in temporary depot areas in the forest for a short time.

\section{Acknowledgements}

This study is funded by The Scientific and Technological Research Council of Turkey (TUBITAK) with the project number 115R048.

\section{References}

Acar, H.H., 1998: Minimization to be Using of Transport Model of Transportation Costs by Trucks at Artvin Forest District. Journal of Agriculture and Forestry 22(5): 491-497.

Acar, H.H., Eroğlu, H., 2001: The Planning of Wood Transport on the Forest Roads. Kafkas University, Artvin Faculty of Forestry Journal 2(1): 61-66.

Akay, A.E., Sessions, J., 2005: Applying the decision support system, TRACER, to forest road design. Western Journal of Applied Forestry 20(3): 184-191. https://doi.org/10.1093/wjaf/20.3.184

Akay, A.E., Erdaş, O., 2007: Planning Transportation of Forest Products by Network Model. İstanbul University Faculty of Forestry Journal 5(2): $1-20$.

Akay, A.E., Kılıç, H.E., 2015: Providing Engineering Solutions to Forest Fire Access Problems Using Network Analysis Method. International Conference on Engineering and Natural Sciences (ICENS). 15-19 May, Skopje (Üsküp), Macedonia.

Akay, A.E., Süslü, H.E., 2017: Developing GIS based Decision Support System for Planning Transportation of Forest Products. Journal of Innovative Science and Engineering 1(1): 6-16.

Başkent, E.Z., 2004: Operations Research, Modelling and Natural Resource Applications. Karadeniz Technical University, Faculty of Forestry, General Publication No: 218, Faculty Publication No: 36. KTU Publishing. Trabzon, 480 p.

Borre, K., Larsson, R., 2011: Low speed maneuvering aids for long vehicle combinations. Msc Thesis. Department of Product and Production Development Division of Design and Human Factors, Chalmers University of Technology, Gothenburg, Sweden, 132 p. Buğday, E., Menemencioğlu, K., 2014: Assessment of Existing Forest Road Standards Conformity for Stumpage Sale in Turkey, II. National Mediterranean Forest and Environment Symposium, 22-24 October, Isparta, Turkey.

CBRT, 2019: The Central Bank of the Republic of Turkey, http:// www.tcmb.gov.tr Last access: 25 March 2019

Chung, W., Sessions, J., 2001: Network 2001-Transportation Planning Under Multiple Objectives. The International Mountain Logging and $11^{\text {th }}$ Pacific Northwest Skyline Symposium, 10-12 December, Seattle, WA, USA.

Enache, A., Stampfer, K., 2015: Machine Utilization Rates, Energy Requirements and Greenhouse Gas Emissions of Forest Road Construction and Maintenance in Romanian Mountain Forests. Journal of Green Engineering 4(4): 325-350. https://doi. org/10.13052/jge1904-4720.445

Erdaş, O., 1997: Forest Roads, Vol. I-II. K.T.Ü. Publishing House, Publication No: 187, Trabzon, 744 p.

GDF, 2012: Strategic Plan (2013-2017). General Directorte of Forestry, Strategy Development Department, Ankara, 98 p. 
Genç, Ç.Ö., Arıcak, B., 2016: Determination of Routes as Type-A Forest Roads for Long Haulage Vehicles: Küre Forest SubDistrict Directorate. Kastamonu University, Faculty of Forestry Journal 16(2): 474-484. https://doi.org/10.17475/kastorman.289757

Ghaffarian, M.R., Sobhani, H., 2007: Optimization of an existing forest road network using Network 2000. Croatian Journal of Forest Engineering 28(2): 185-193.

Gümüş, S., Hatay, T.Y., Okan, S.Ü., 2019: An Evaluation of General Situation and Importance of Forest Roads: Turkish Forestry. $2^{\text {nd }}$ International Symposium of Forest Engineering and Technologies, (FETEC 2019), 4-6 September, Tiran. Albania.
Karabenli, S.T., 2018: Determining Effects of Improving Forest Road Standards on Total Economic Value of Forest Products and Timber Hauling Activities. Msc Thesis, Bursa Technical University, Bursa, $77 \mathrm{p}$.

Sessions, J., 1985: A heuristic algorithm for the solution of the fixed and variable cost transportation problem. in Proc. of the 1985 Symposium on Systems Analysis in Forest Resources, Dress and Field (eds.). Society of American Foresters, 9-11 December, Athens, GA, USA.

Strandström, M., 2016: Timber harvesting and long-distance transportation of roundwood 2015. Metsätehon tuloskalvosarja $4 b / 2016$.

(C) 2021 by the authors. Submitted for possible open access publication under the terms and conditions of the Creative Commons Attribution (CC BY) license (http://creativecommons.org/licenses/by/4.0/).

Received: January 21, 2020

Accepted: July 15, 2020
Authors' addresses:

Prof. Abdullah E. Akay, PhD

e-mail: abdullah.akay@btu.edu.tr

Bursa Technical University

Faculty of Forestry

16310 Bursa

TURKEY

Prof. Hasan Serin, PhD

e-mail: hasanserin@ksu.edu.tr

Asst. prof. Mehmet Pak, PhD

e-mail: mpak@ksu.edu.tr

Kahramanmaraş Sütçü İmam University

Faculty of Forestry

46100 Kahramanmaraş

TURKEY

Prof. John Sessions, PhD

e-mail: john.sessions@oregonstate.edu

Oregon State University

College of Forestry

FERM Department

Corvallis, 97331 Oregon

USA

Asst. prof. Ebru Bilici, PhD *

e-mail: ebru.bilici@giresun.edu.tr

Giresun University

Dereli Vocational School

Forestry Department

28950 Giresun

TURKEY

* Corresponding author 